\title{
Substantiation of the conditions of obtaining porous carbon materials from pyrolyzed wood wastes by chemical activation of $\mathrm{H}_{3} \mathrm{PO}_{4}$
}

\author{
Oleg Kuzmin ${ }^{1}$, Tatiana Shendrik ${ }^{2}$, Valentyna Zubkova ${ }^{3}$
}

\section{1 - National University of Food Technologies, Kyiv, Ukraine \\ 2 - L.M. Litvinenko Institute of Physical-Organic Chemistry and Coal Chemistry \\ NAS, Kyiv, Ukraine \\ 3 - Jan Kochanowski University in Kielce, Kielce, Poland}

Keywords:

Pyrolysis

Waste

Activation

Nanopore

Adsorbent

\section{Article history:}

Received 20.12.2016

Received in revised

form 13.03.2017

Accepted 30.03.2017

\section{Corresponding \\ author:}

Tatiana Shendrik

E-mail:

shendriktg@gmail.com

DOI: $10.24263 / 2304-$ 974X-2017-6-1-12

\section{Abstract}

Introduction. The purpose of this publication is to search for alternative materials - food industry wastes; valuation of it's use in the production of porous carbon materials (PCM) for use in water treatment systems.

Materials and methods. Pyrolyzed wood waste (PWW) of the meat processing industry as raw material for the production of sorbents. Chemical activation of PWW by orthophosphoric acid. Using the adsorption-desorption methods of nitrogen, the porous structure was determined at $77 \mathrm{~K}$; mesopore distribution by size and mesopore's volume - by $B J H$-method; distribution of micropores by size - using QSDFT-method; volume of micropores - by Dubinin-Radushkevich method; subnanopor's volume - by QSDFT-method.

Results and discussion. The microporous structure has the following characteristics: pore diameters are in the range of $D_{m i}=0,60-2,5 \mathrm{~nm}$, mostly represented by pores with a diameter of 0,$87 ; 1,56 \mathrm{~nm}$; volume of micropores $-V_{m i}=0,091 \mathrm{~cm}^{3} / \mathrm{g}$; differential pore volume $d V_{m i} / d D=(0,021-0,166) \cdot 10^{-2} \mathrm{~cm}^{3} / \mathrm{g}$; micropores are about $49 \%$ of the total pore volume. According to the breakdown of micropores by size we can identify the range of values of $D_{m i}=0,5-2,5 \mathrm{~nm}$ with two peaks: at $\sim 0,9 \mathrm{~nm}$ and at $\sim 1,6 \mathrm{~nm}$. Mesoporous structure has the following characteristics: pore diameters are in the range of $D_{m e}=3,3-50,0$ $\mathrm{nm}$, most represented pores are with a diameter of $3,69 \mathrm{~nm}$; mesopore's volume varies in the range of $V_{m e}=0,005-0,049$ $\mathrm{cm}^{3} / \mathrm{g}$; pore surface area is $S_{m e}=5,7-28,0 \mathrm{~m}^{2} / \mathrm{g}$; differential pore volume: $d V_{m e} / d D=(0,06-2,58) \cdot 10^{-4} \mathrm{~cm}^{3} / \mathrm{g}$; differential pore area: $d S_{m e} / d D=(0,001-0,305) \mathrm{m}^{2} / \mathrm{g}$; fraction of mesopores in the total pore volume is $3-26 \%$. Curves of pore's differential volume and differential area of pore's surface at the interval of $D=15,3-50,0$ $\mathrm{nm}$ are located at the static area. Maximum located at the area of the smaller pore's diameter at the differential pore volume $d V_{m e} / d D=2,58 \cdot 10^{-4} \mathrm{~cm}^{3} / \mathrm{g}$ is observed at the point of $3,69 \mathrm{~nm}$ at the interval $D=2,5-15,3 \mathrm{~nm}$. The most number of mesopores located at the range of $D=2,5-15,3 \mathrm{~nm}$. The cited data shows that the proposed method allows to get PCM with a high output of $87,6 \%$. The obtained PCM has a low rate of specific surface are $S_{B E T}=257,0 \mathrm{~m}^{2} / \mathrm{g}$ and pore space. Total pore volume is $V_{\Sigma}=0,187$ $\mathrm{cm}^{3} / \mathrm{g}$.

Conclusion. An energy-saving method is proposed for the production of PCM from secondary «renewable» resources PWW, for use in water treatment systems. 


\section{Introduction}

Today it is known that organic matter of carbon-containing material consists of carbon (96,0\%), hydrogen $(1,0-2,5 \%)$, nitrogen $(0,3-1,5 \%)$, sulfur $(0,0-1,0 \%)$.

The PCM is made of materials that forms a solid carbon residue [1-8]. These matherials areas follows: wood $-36 \%$, coal $-28 \%$, brown coal $-14 \%$, peat $-10 \%$ coconut shell $-10 \%$ organic materials and waste $-2 \%$ (Figure 1) [1].

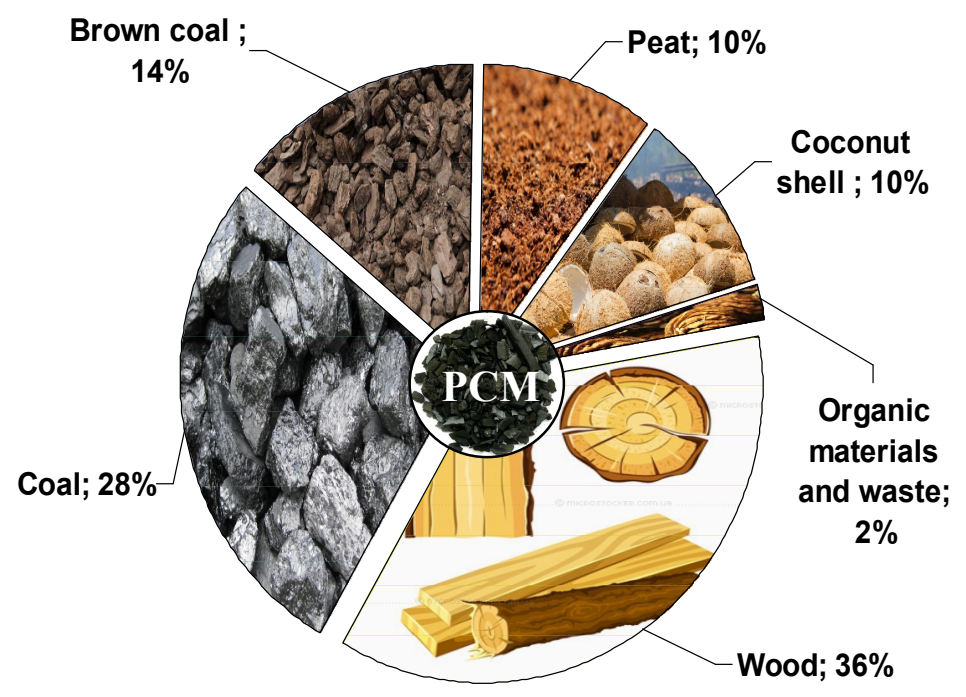

Figure 1. PCM receiving characteristics

Only $2 \%$ of organic material and waste are used to produce PCM [1]. Therefore, there is urgent need for an alternative materials. The search for these materials should involve existing technologies of food industry. Wastes of these industries can be used to produce adsorbents [1-22].

Today are known two ways of getting PCM - with the chemical $[1-6,9,12,13,15,16,19$, $21,22,24,26,27]$ and physical activation $[1,15,17,21,27]$. Benefits of chemical activation are: one-step process; low activation temperature; short activation time; large output; developed surface; controlled microporosity is well developed [26]. The chemical activation involves usage of activating agent $\left(\mathrm{ZnCl}_{2}\right.$ [4], $\mathrm{H}_{3} \mathrm{PO}_{4}[2,3,9,12,16], \mathrm{NaOH}[26], \mathrm{KOH}[24,26]$, et al.), administered by impregnation, followed by carbonization of raw materials in the atmosphere or inert gases and activation [27].

Today are known many ways of receiving of PCM (Yorgun, Yildiz, 2015; Kumar, Jena, 2017; Kucherenko et al, 2010; Lillo-Rodenas, 2003) [2, 4, 24, 26], such as (Pat. 61059 Ukraine): grinding carbon-containing material with (1-2) $10^{-3} \mathrm{~m}$, mixing with $\mathrm{KOH}$ in solid form in a weight ratio $-1: 0,5-1: 1$, carbonization and activation at mode heatstroke at $\mathrm{T}=873-1073 \mathrm{~K}$, cleaning with water and drying.

This method of receiving of PCM (Pat. 61059 Ukraine) has the following disadvantages: raw materials grinding has a high energy consumption; the small size of raw materials' fractions - it became charcoaled after carbonization and activation and evaporates with the gaseous components; high temperature carbonization and activation of PCM; activation in a heatstroke mode causes tearing of the structure and reduction of PCM shares; low rate of PCM release.

The most promising raw material for PCM - PWW is formed by pyrolysis of wood chips 
(Kuzmin, Shendrik, 2016) [1]. This includes: the stage of grinding materials is absent due to the use of wood chips of PCM witht the size of $1 \times b \times h=(6 \times 12 \times 3) \cdot 10^{-3} \mathrm{~m}$; PCM fractional increases up to $3,6 \cdot 10^{-3}>\mathrm{d} \geq 1,0 \cdot 10^{-3} \mathrm{~m}$; temperature reduction of charcoal carbonization and activation up to $\mathrm{T}=773-973 \mathrm{~K}$; absence of heat stroke of activation due to carbonization at non-isothermal heating and isothermal heating at activation; output increase of PCM ratio.

One of the promising activating agents is orthophosphoric acid (Yorgun, Yildiz, 2015; Kwiatkowski et al, 2017; Ould-Idriss et al, 2011; Mahmood et al, 2017; Kumar, Jena, 2017) $[2,3,9,12,16]$ with mass part (MP) $\mathrm{H}_{3} \mathrm{PO}_{4} \geq 85 \%$, which is added to the carbonaceous material and can withstand up to full impregnation, allowing acid to interact with organic and mineral components, with the formation of water-soluble substances washed with PCM $[2,3,16]$. During the interaction of organic acid and component of PWW produced are oxygen function and sulfate formed pore space. Thus, the use of $\mathrm{H}_{3} \mathrm{PO}_{4}$ allows to receive $\mathrm{PCM}$ with a low charcoal $[9,12]$.

Variation of MP activating agent in relation to PWW can affect the surface pores factor, yield ratio of PCM, the volume of wastewater [23, 25, 28-34].

A mixture of raw material/agent during carbonization and activation undergoing nonisothermal heating up to the activation temperature during the subsequent isothermal aging. In the scope of PWW is the formation of thermal degradation of products of low organic matter of PWW and PWW products of chemical reactions with acid takes place. Their output forms the spatial framework of PWW within. This leads to the formation of micropores and subnanopor and, consequently, increases the specific surface area and pore volume of the total. This improves adsorption characteristics PCM (Shendrik et al, 2003; Kucherenko et al, 2010; Zubkova, 2011) [23-25]. Fractional composition determined by PCM through MP residue on sieves with holes with a diameter of 3,6 mm, $1,0 \mathrm{~mm}$ and pallet.

It has been proved that PWW is an alternative carbon-containing raw material for PCM (Kuzmin, Shendrik, 2016) [1].

The aim of this work is the search for alternative materials of available technology of food industry. The wastes of which can be used for a production of PCM.

\section{Materials and methods}

Conditions for PCM production are presented at Table 1.

Obtained PWW is dried in the open air $\left(T_{l}=293-298 \mathrm{~K} ; W_{l}=67-82 \% ; v_{l}=1-2 \mathrm{~m} / \mathrm{s}\right)$ during $\tau_{I}=(336-504) \cdot 60^{2} \mathrm{~s}$, followed by more drying at $T_{2}=373-383 \mathrm{~K}$ up to air-dry state with humidity of $W_{2}=4-8 \%$.

An orthophosphoric acid with MP of $\mathrm{H}_{3} \mathrm{PO}_{4}-85 \%$ used as an activating agent for impregnating PWW/acid in mass ratio (MR) 1:0,5-1:1. The received mixture withstands for $\tau_{2}=(18-24) \cdot 60^{2} \mathrm{~s}$ at $T_{3}=291-295 \mathrm{~K}$ and PWW dried to receive a constant weight of MP moisture $W_{3}=4-8 \%$ at $T_{4}=373-383 \mathrm{~K}$. Activation carried out in a stream of argon with a volumetric flow $-Q_{1} \leq 5,6 \cdot 10^{-7} \mathrm{~m}^{3} / \mathrm{s}$ with drying bubbling after $96 \%$ in sulfuric acid under non-isothermal heating $0,07 \mathrm{deg} . / \mathrm{s}$ upto activation temperature $T_{5}=773-973 \mathrm{~K}$ and isothermal aging for $\tau_{3}=1 \cdot 60^{2} \mathrm{~s}$ at temperature activation and non-isothermal cooling $-0,1$ deg./s in a stream of argon to a temperature $T_{6}=323 \mathrm{~K}$.

The received PCM cleaned from activating agent with a usage of water for $\tau_{4}=300-600 \mathrm{~s}$ and dried at a temperature $T_{T}=373-383 \mathrm{~K}$ up to level of humidity $W_{4}=4-8 \%$ with the rate of release of PCM $Y_{l}=80-90 \%$, followed by fractioning with the help of MP residue on sieves with holes: $d \geq 3,6 \cdot 10^{-3} \mathrm{~m}-\mathrm{MP} \leq 2,5 \% ; 3,6 \cdot 10^{-3}>\mathrm{d} \geq 1,0 \cdot 10^{-3} \mathrm{~m}-\mathrm{MP} \geq 95,5 \% ; \mathrm{d}<1,0 \cdot 10^{-3} \mathrm{~m}-$ $\mathrm{MP} \leq 2,0 \%$ with the following selection of working faction on a sieve with holes $3,6 \cdot 10^{-3}>$ $\mathrm{d} \geq 1,0 \cdot 10^{-3}$. 


\section{Terms of PCM}

Table 1

\begin{tabular}{|c|c|c|c|}
\hline Symbol & Characteristic & $\begin{array}{l}\text { Experimental } \\
\text { data }\end{array}$ & Rationed data \\
\hline$T_{1}$ & The temperature drying in the open air, $\mathrm{K}$ & 295 & $293-298$ \\
\hline$W_{1}$ & Relative humidity, $\%$ & 74 & $67-82$ \\
\hline$v_{1}$ & Air traffic speed, $\mathrm{m} / \mathrm{s}$ & 1,5 & $1-2$ \\
\hline$\tau_{1}$ & PCM drying time outdoors, $\mathrm{s}$ & $336 \cdot 60^{2}$ & $(336-504) \cdot 60^{2}$ \\
\hline$T_{2}$ & $\begin{array}{l}\text { The temperature drying in the drying cabinet, } \\
\mathrm{K}\end{array}$ & 373 & $373-383$ \\
\hline \multirow[t]{3}{*}{$W_{2}$} & MP moisture PWW, \% & 6,58 & $4-8$ \\
\hline & $\mathrm{MP} \mathrm{N}_{3} \mathrm{PO}_{4}, \%$ & 85 & 85 \\
\hline & MR PWW/acid, kg/kg & $1: 1$ & $1: 0,5-1: 1$ \\
\hline$\tau_{2}$ & Time withstand PWW with acid, s & $24 \cdot 60^{2}$ & $(18-24) \cdot 60^{2}$ \\
\hline$T_{3}$ & PWW holding temperature acid, $\mathrm{K}$ & 294 & $291-295$ \\
\hline$T_{4}$ & Drying temperature, $\mathrm{K}$ & 381 & $373-383$ \\
\hline$W_{3}$ & MP moisture PWW, \% & 6,02 & $4-8$ \\
\hline \multirow[t]{3}{*}{$Q_{1}$} & The volumetric flow of argon, $\mathrm{m}^{3} / \mathrm{s}$ & $5,6 \cdot 10^{-7}$ & $\leq 5,6 \cdot 10^{-7}$ \\
\hline & Non-isothermal heating, deg./s & 0,07 & $\leq 0,07$ \\
\hline & MP sulfuric acid, $\%$ & 96 & 96 \\
\hline$T_{5}$ & Activation temperature, $\mathrm{K}$ & 773 & $773-973$ \\
\hline \multirow[t]{2}{*}{$\tau_{3}$} & The time of activation, $\mathrm{s}$ & $1 \cdot 60^{2}$ & $1 \cdot 60^{2}$ \\
\hline & Non-isothermal cooling, deg./s & 0,1 & $\leq 0,1$ \\
\hline$T_{6}$ & The final temperature after cooling PCM, K & 323 & $\leq 323$ \\
\hline$\tau_{4}$ & Time cleaning PCM from activating agent, $\mathrm{s}$ & 600 & $300-600$ \\
\hline$T_{7}$ & $\begin{array}{l}\text { The temperature drying in the drying cabinet, } \\
\mathrm{K}\end{array}$ & 378 & $373-383$ \\
\hline$W_{4}$ & MP moisture PCM, \% & 4,92 & $4-8$ \\
\hline \multirow[t]{2}{*}{$Y_{1}$} & PCM yield ratio, $\%$ & 87,6 & $80-90$ \\
\hline & $\begin{array}{l}\text { MP remnant of PCM }(\%) \text { in the sieve with } \\
\text { holes, m: } \\
d \geq 3,6 \cdot 10^{-3} \\
3,6 \cdot 10^{-3}>d \geq 1,0 \cdot 10^{-3} \\
d<1,0 \cdot 10^{-3}\end{array}$ & $\begin{array}{l}57,6 \\
26,8 \\
15,6\end{array}$ & $\begin{array}{c}\mathrm{MP} \leq 2,5 \\
\mathrm{MP} \geq 95,5 \\
\mathrm{MP} \leq 2,0\end{array}$ \\
\hline
\end{tabular}


Figure 2 shows the stages of PCM production; Figure 3 - general scheme of PCM obtaining according to experimental data from Table 1.
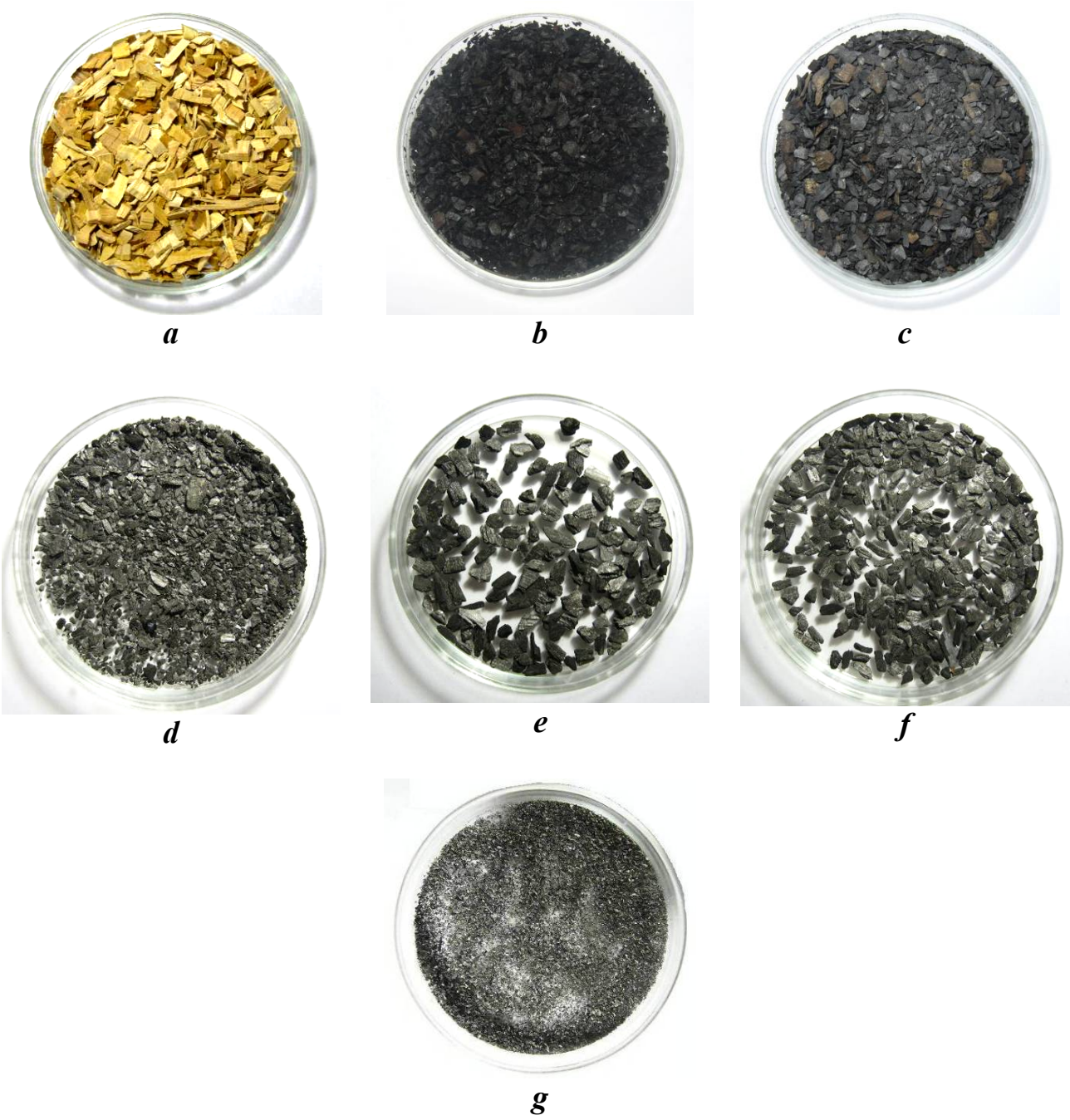

Figure 2. Stage receiving PCM:

$\mathrm{a}$ - technological chips of oak large $(6 \times 12 \times 3) \cdot 10^{-3} \mathrm{~m} ; \mathrm{b}-\mathrm{PWW}$ with MP moisture $\mathrm{W}=43,01 \%$; $\mathrm{c}-\mathrm{PWW}$ after drying of moisture MP $\mathrm{W}=6,58 \% ; \mathrm{d}-\mathrm{PCM}$ to fractionation;

e - PCM after fractionation of $\mathrm{d} \geq 3,6 \cdot 10^{-3} \mathrm{~m} ; \mathrm{f}-\mathrm{PCM}$ after fractionation of $3,6 \cdot 10^{-3}>\mathrm{d} \geq 1,0 \cdot 10^{-3} \mathrm{~m}$; $\mathrm{g}-\mathrm{PCM}$ after fractionation of $\mathrm{d}<1,0 \cdot 10^{-3} \mathrm{~m}$ 


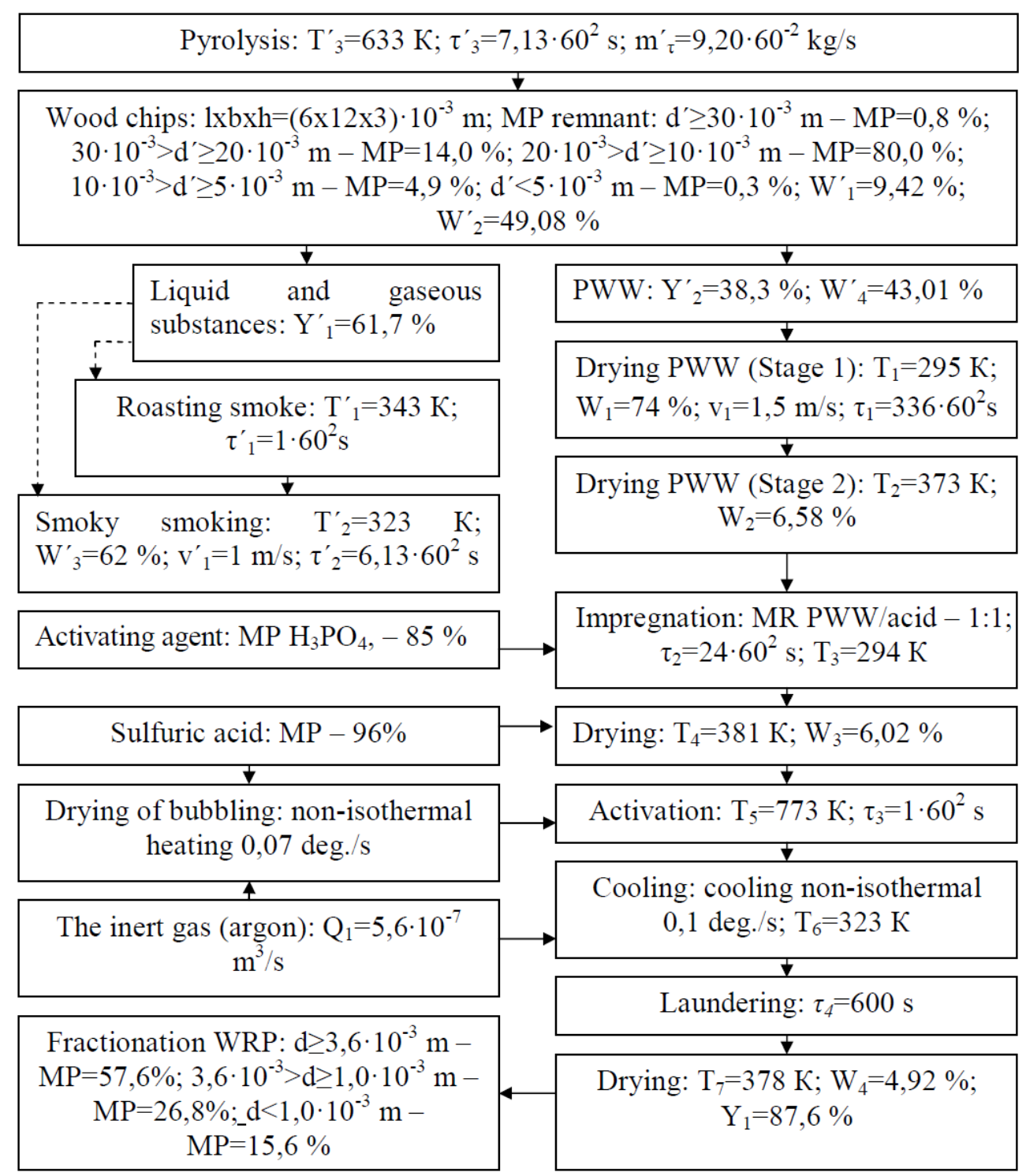

Figure 3. The general scheme of $\mathrm{PCM}$ receiving as per experimental data

PWW dried for $\tau_{1}=336 \cdot 60^{2} \mathrm{~s}$ outdoors $\left(T_{l}=295 \mathrm{~K} ; W_{l}=74 \% ; v_{l}=1,5 \mathrm{~m} / \mathrm{s}\right)$, followed by drying at the drying cabinet at $T_{2}=373 \mathrm{~K}$ to air-dry state with MP moisture $-W_{2}=6,58 \%$. Phosphoric acid with MP $\mathrm{H}_{3} \mathrm{PO}_{4}-85 \%$ injected by impregnation of $\mathrm{PWW}-\mathrm{H}_{3} \mathrm{PO}_{4}$ and kept for $\tau_{2}=24 \cdot 60^{2} \mathrm{~s}$ at temperature $T_{3}=294 \mathrm{~K}$ and dried up to a moisture obtained at MP PWW $W_{3}=6,02 \%$ at $T_{4}=381 \mathrm{~K}$. The volume of solution has been choosed to create MR PWW/acid $1: 1 \mathrm{~kg} / \mathrm{kg}$. Activation was performed in a vertical cylindrical tubular reactor made of steel, with thickness of $3 \mathrm{~mm}$, diameter of cylinder $-0,15 \mathrm{~m}$, height $-0,3 \mathrm{~m}$. 
The reactor was purged with argon volumetric flow of $Q_{I}=5,6 \cdot 10^{-7} \mathrm{~m}^{3} / \mathrm{s}$, drained bubbling through concentrated sulfuric acid (96\%). The heating of reactor's furnace has been switched on after $0,17 \cdot 60^{2} \mathrm{~s}$ after the start of argon input. The temperature mode of process included a period of non-isothermal heating $(0,07 \mathrm{deg} . / \mathrm{s})$ up to an activation temperature, isothermal holding at this temperature for $\tau_{3}=1 \cdot 60^{2} \mathrm{~s}$ and rapid cooling in a stream of argon cooled at non-isothermal $0,1 \mathrm{deg} . / \mathrm{s}$ to $T_{\sigma}=323 \mathrm{~K}$. The activation temperature was $T_{5}=773 \mathrm{~K}$ when activated via $\mathrm{H}_{3} \mathrm{PO}_{4}$.

Samples of PCM activating agent washed with distilled water for $\tau_{4}=600 \mathrm{~s}$ and dried at $T_{7}=378 \mathrm{~K}$ to humidity $W_{4}=4,92 \%$ of the rate of release of PCM $Y_{1}=87,6 \%$. Fractionation PCM remnant of MP conducted on sieves with holes: $d \geq 3,6 \cdot 10^{-3}-\mathrm{MP}=57,6 \% ; 3,6 \cdot 10^{-}$ ${ }^{3}>d \geq 1,0 \cdot 10^{-3}-\mathrm{MP}=26,8 \% ; d<1,0 \cdot 10^{-3}$ (pallet) $-\mathrm{MP}=15,6 \%$ with the following collection of working fractions on sieves of $3,6 \mathrm{~mm}$ and $1,00 \mathrm{~mm} \mathrm{MP}-84,4 \%$.

\section{Results and discussions}

Characteristics of porous structure was determined on a basis of isotherms adsorptiondesorption of nitrogen at $T=77 \mathrm{~K}$ in the range of relative pressure $\mathrm{P} / \mathrm{P}_{0}=0,00-1,00$ (device Quantachrome Autosorb 6B) (Figure 4).

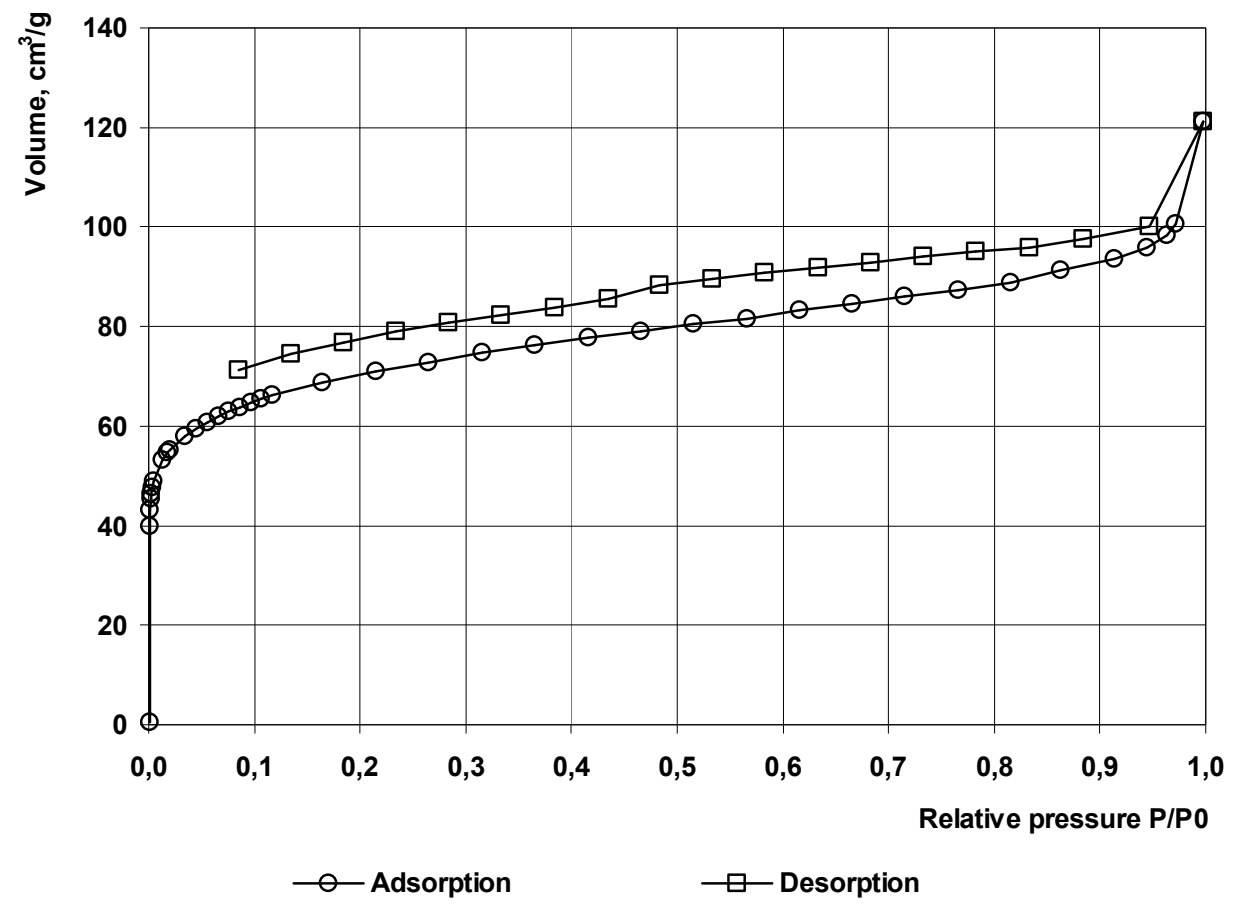

Figure 4. Isotherms of adsorption-desorption of nitrogen at $\mathrm{PCM}$ at $\mathrm{T}=77 \mathrm{~K}$

The obtained isotherms of type II - according to Brunauer S. classification [28], per multimolecular adsorption. Sorption hysteresis loop approaching the point of relative pressure $P / P_{0}=0,4$, indicating a predominance of micropores of meso- and macropores. 
Figure 5 shows the distribution of micropores by the size of sample.

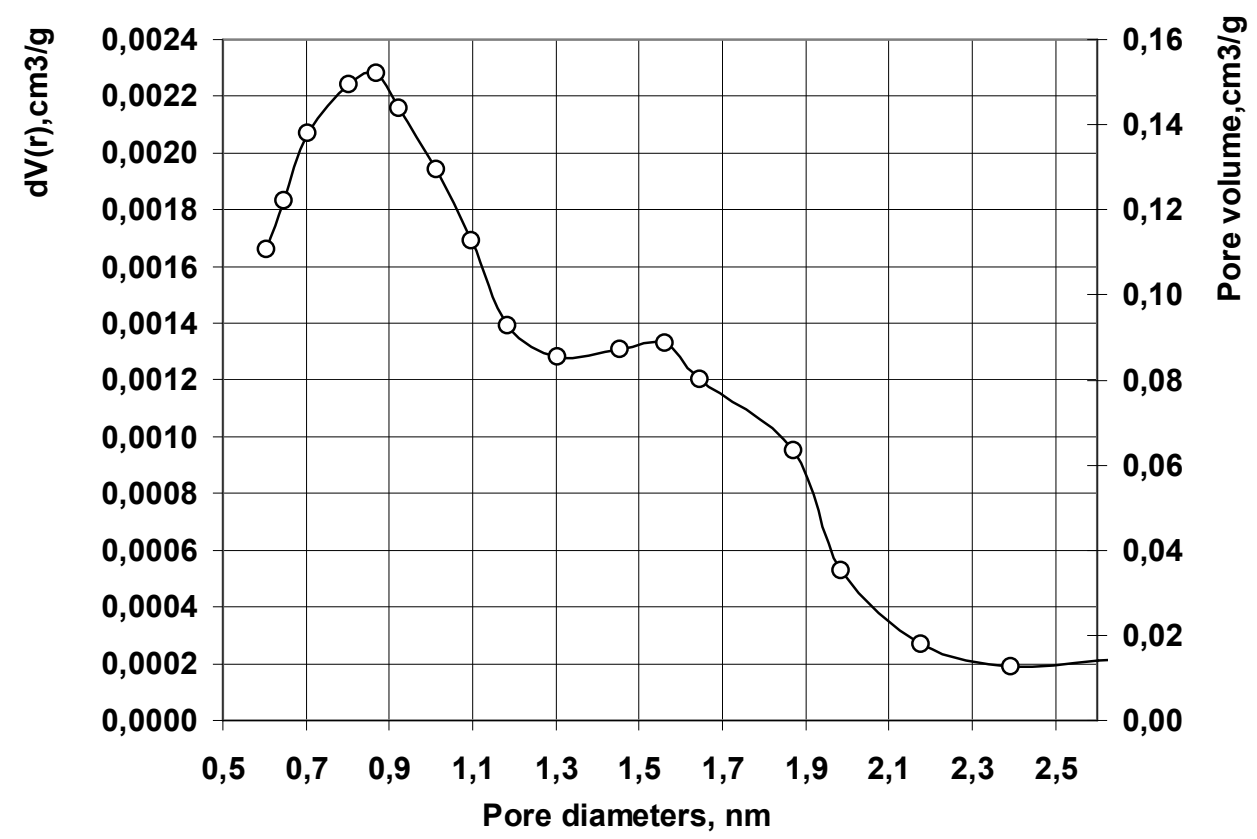

Figure 5. Distribution of micropores in size of the sample PCM - (pore diameter dependence of the differential pore volume) by QSDFT-method

Table 2 presents the results of a study by $B J H$-method mesopores' size distribution. Figures 6-10 shows the distribution of mesopores ( $B J H$-method) the size of the sample and the corresponding volumes accumulated in these pores.

The microporous structure has the following characteristics: pore diameters are in the range of $D_{m i}=0,60-2,5 \mathrm{~nm}$, mostly represented with pores with a diameter of 0,$87 ; 1,56 \mathrm{~nm}$; volume of micropores $-V_{m i}=0,091 \mathrm{~cm}^{3} / \mathrm{g}$; differential pore volume $d V_{m i} / d D=(0,021$ $0,166) \cdot 10^{-2} \mathrm{~cm}^{3} / \mathrm{g}$; micropores fraction of the total pore volume is $49 \%$.

As per allocation of micropores by size areas of values (Figure 5) $D_{m i}=0,5-2,5 \mathrm{~nm}$ with two peaks: at $\sim 0,9 \mathrm{~nm}$ and at $\sim 1,6 \mathrm{~nm}$ can be identified.

Mesoporous structure has the following characteristics: pore diameters are in the range of $D_{m e}=3,3-50,0 \mathrm{~nm}$, most represented pores with a diameter of 3,69 nm; mesopore volume varies in the range of $V_{m e}=0,005-0,049 \mathrm{~cm}^{3} / \mathrm{g}$; pore surface area $-S_{m e}=5,7-28,0$ $\mathrm{m}^{2} / \mathrm{g}$; differential pore volume $d V_{m e} / d D=(0,06-2,58) \cdot 10^{-4} \mathrm{~cm}^{3} / \mathrm{g}$; differential pore area $d S_{m e} / d D=(0,001-0,305) \mathrm{m}^{2} / \mathrm{g}$; fraction of mesopores in the total pore volume is $3-26 \%$ (Figure 6-10).

Curves of pore differential volume and pore differential surface area at the interval of $D=15,3-50,0 \mathrm{~nm}$ are in the static area. Maximum located in a smaller diameter pores at the pore's differential volume $d V_{m e} / d D=2,58 \cdot 10^{-4} \mathrm{~cm}^{3} / \mathrm{g}$ at the point of $3,69 \mathrm{~nm}$ at the interval $D=2,5-15,3 \mathrm{~nm}$ is observed. The most number of mesopores located at a range of $D=2,5-$ $15,3 \mathrm{~nm}$. 
Table 2

Distribution of mesopores' size by BJH-method

\begin{tabular}{|c|c|c|c|c|c|c|}
\hline $\begin{array}{c}\text { Pore } \\
\text { diameter, } \\
\text { nm }\end{array}$ & $\begin{array}{c}\text { Pore } \\
\text { volume, } \\
\mathrm{cm}^{3} / \mathrm{g}\end{array}$ & $\begin{array}{c}\text { Pore } \\
\text { differential } \\
\text { volume, } \mathbf{c m}^{3} / \mathrm{g}\end{array}$ & $\begin{array}{c}\text { Pore } \\
\text { surface } \\
\text { area, } \\
\mathbf{m}^{2} / \mathbf{g}\end{array}$ & $\begin{array}{c}\text { Pore } \\
\text { differential } \\
\text { area, } \mathbf{m}^{2} / \mathrm{g}\end{array}$ & $\begin{array}{c}\mathrm{dV}(\operatorname{logr}), \\
\mathrm{cm}^{3} / \mathrm{g}\end{array}$ & $\begin{array}{c}\mathrm{dS}(\operatorname{logr}) \\
\mathrm{cm}^{3} / \mathrm{g}\end{array}$ \\
\hline 3,30 & 0,005 & 0,0002510 & 5,73 & 0,304640 & 0,095 & 115,47 \\
\hline 3,69 & 0,011 & 0,0002578 & 12,47 & 0,284850 & 0,108 & 118,59 \\
\hline 4,14 & 0,016 & 0,0002060 & 17,21 & 0,210570 & 0,093 & 94,78 \\
\hline 4,68 & 0,019 & 0,0001022 & 19,79 & 0,090060 & 0,054 & 46,98 \\
\hline 5,36 & 0,021 & 0,0000731 & 21,81 & 0,056194 & 0,044 & 33,62 \\
\hline 6,21 & 0,024 & 0,0000541 & 23,46 & 0,035971 & 0,038 & 24,87 \\
\hline 7,33 & 0,026 & 0,0000402 & 24,84 & 0,022830 & 0,033 & 18,45 \\
\hline 8,86 & 0,029 & 0,0000255 & 25,85 & 0,012418 & 0,025 & 11,71 \\
\hline 11,24 & 0,031 & 0,0000168 & 26,69 & 0,006473 & 0,021 & 7,71 \\
\hline 15,35 & 0,034 & 0,0000092 & 27,38 & 0,002531 & 0,017 & 4,18 \\
\hline 27,94 & 0,048 & 0,0000061 & 28,01 & 0,001335 & 0,021 & 2,72 \\
\hline 416,58 & 0,072 & 0,0000009 & 28,45 & 0,000008 & 0,025 & 0,24 \\
\hline
\end{tabular}

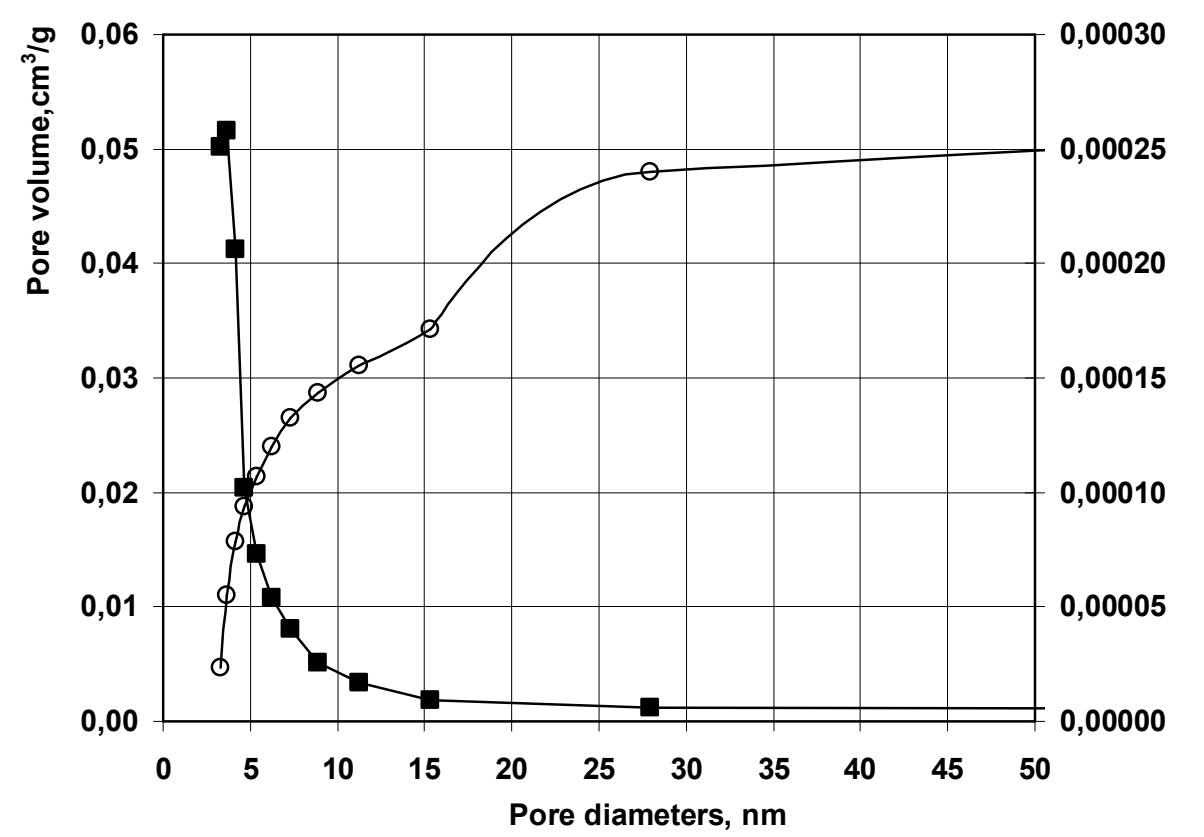

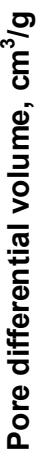

- Pore volume, $\mathrm{cm} 3 / \mathrm{g}$

$\rightarrow-$ Pore differential volume, $\mathrm{cm} 3 / \mathrm{g}$

Figure 6. Distribution of mesopores by size of the sample PCM - (pore diameter dependence of pore volume and pore volume differential) by BJH-method 


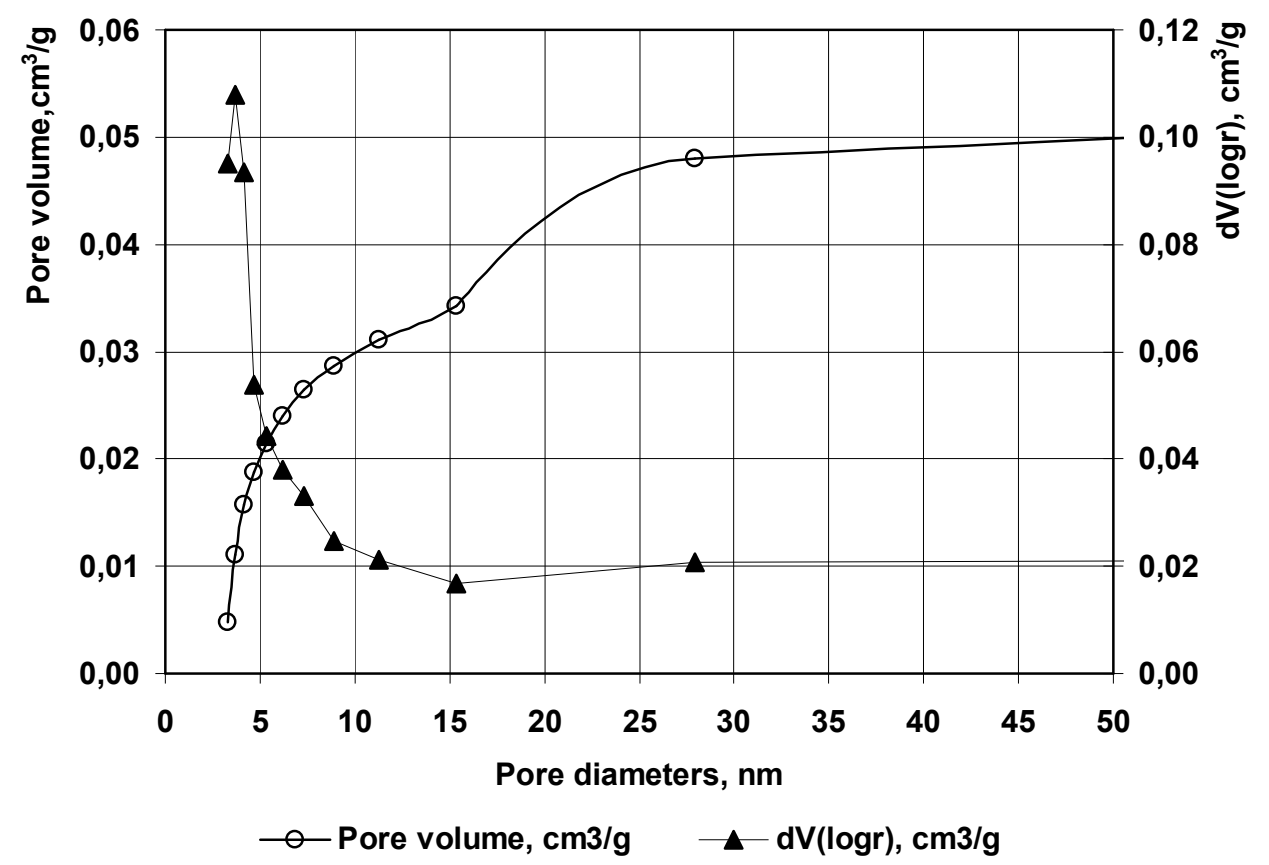

Figure 7. Distribution of mesopores by size of the sample PCM - (dependence pore diameter of pores and volume $\mathrm{dV}(\operatorname{logr}))$ by BJH-method

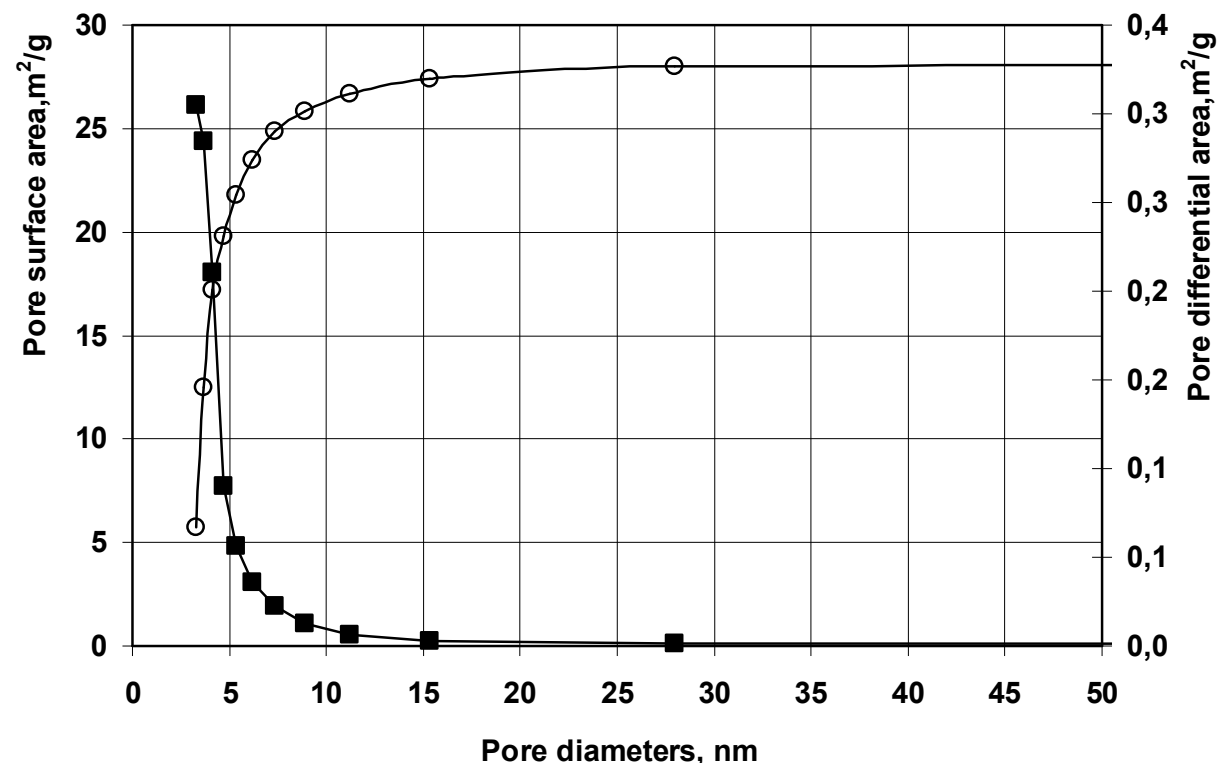

-Pore surface area, $\mathrm{m} 2 / \mathrm{g} \longrightarrow$ Pore differential area, $\mathrm{m} 2 / \mathrm{g}$

Figure 8. Distribution of mesopores by size of the sample PCM - (pore diameter dependence of surface area and pore surface area differential) by BJH-method 
It was measured characteristics of PCM: $Y$ - yield ratio of PCM (\%); $S_{B E T}-$ pore surface area $\left(\mathrm{m}^{2} / \mathrm{g}\right) ; V_{\Sigma}$ - pore total volume $\left(\mathrm{cm}^{3} / \mathrm{g}\right) ; V_{m a}-$ macropore volume $\left(\mathrm{cm}^{3} / \mathrm{g}\right) ; V_{m e}-$ mesopore volume $\left(\mathrm{cm}^{3} / \mathrm{g}\right) ; V_{m i}-$ micropores volume $\left(\mathrm{cm}^{3} / \mathrm{g}\right)$.

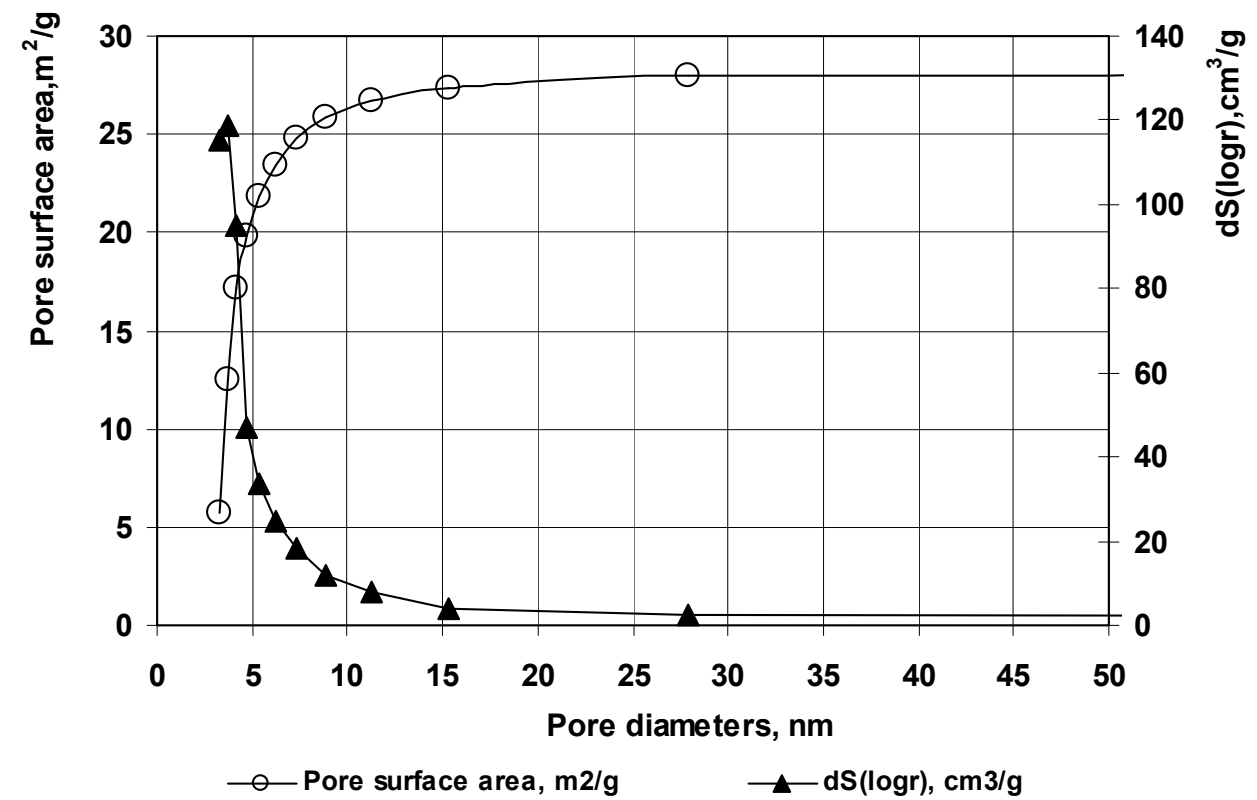

Figure 9. Distribution mesopores the size of the sample PCM - (pore diameter dependence of surface area and pore $\mathrm{dS}(\log ))$ by the BJH-method

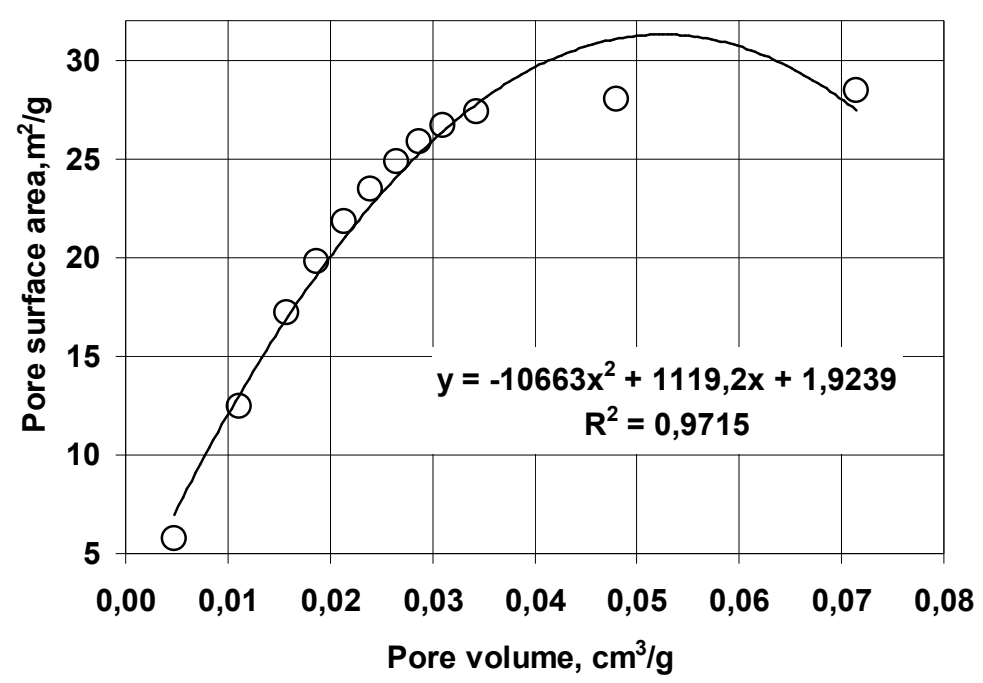

Figure 10. Distribution of mesopores by size of the sample PCM - (pore volume of pore surface area) by the BJH-method 
Terms of PCM and its characteristics are shown at Table 3.

Table 3

Terms of PCM and its characteristics

\begin{tabular}{|c|c|c|c|c|}
\hline Characteristic & \multicolumn{2}{|c|}{$\begin{array}{c}\text { Method PCM (Pat. } 61059 \\
\text { Ukraine) }\end{array}$} & \multicolumn{2}{|c|}{$\begin{array}{l}\text { Method of PCM } \\
\text { experimental data }\end{array}$} \\
\hline Type of raw & \multicolumn{2}{|c|}{ lignite } & \multicolumn{2}{|c|}{ PWW } \\
\hline $\begin{array}{l}\text { The temperature } \\
\text { activation, } K\end{array}$ & \multicolumn{2}{|c|}{873} & \multicolumn{2}{|c|}{773} \\
\hline Activating agent & \multicolumn{2}{|c|}{$\mathrm{KOH}$} & \multicolumn{2}{|c|}{$\mathrm{H}_{3} \mathrm{PO}_{4}$} \\
\hline MR raw/agent, $\mathrm{kg} / \mathrm{kg}$ & \multicolumn{2}{|c|}{$1: 1$} & \multicolumn{2}{|c|}{$1: 1$} \\
\hline$Y, \%$ & \multicolumn{2}{|c|}{40,0} & \multirow{2}{*}{\multicolumn{2}{|c|}{87,6}} \\
\hline$S_{B E T}, \mathrm{~m}^{2} / \mathrm{g}$ & \multicolumn{2}{|c|}{980,0} & 257,0 & \\
\hline$V_{\Sigma}, \mathrm{cm}^{3} / \mathrm{g}$ & 0,500 & $100 \%$ & 0,187 & $100 \%$ \\
\hline$V_{m a}, \mathrm{~cm}^{3} / \mathrm{g}$ & 0,040 & $8 \%$ & 0,047 & $25 \%$ \\
\hline$V_{m e}, \mathrm{~cm}^{3} / \mathrm{g}$ & 0,220 & $44 \%$ & 0,049 & $26 \%$ \\
\hline$V_{m i}, \mathrm{~cm}^{3} / \mathrm{g}$ & 0,240 & $48 \%$ & 0,091 & $49 \%$ \\
\hline
\end{tabular}

\section{Conclusions}

An energy-saving method is proposed for the production of PCM from secondary «renewable» resources - PWW.

The data show that the proposed method allows to get PCM with high yield of $87,6 \%$ compared to the method of obtaining of PCM (Pat. 61059 Ukraine) - 40,0\%. The PCM has a low proportion surface $S_{B E T}=257,0 \mathrm{~m}^{2} / \mathrm{g}$ with respect to PCM (Pat. 61059 Ukraine) $S_{B E T}=980,0 \mathrm{~m}^{2} / \mathrm{g}$ and pore space - total pore volume $V_{\Sigma}=0,187 \mathrm{~cm}^{3} / \mathrm{g}$ to $V_{\Sigma}=0,500 \mathrm{~cm}^{3} / \mathrm{g}$. Moreover, the ratio of micropores to the total volume of the two options for $49 \%$ and $48 \%$ is unchanged, and the ratio of macropores in the experimental sample (25\%), increased in relation to the prototype ( $8 \%$ ), and the ratio of mesopores in the experimental sample $(26 \%$ ) reduced relative to the prototype (44\%).

It can be concluded that the proposed method production of PCM from PWW, produced when smoking foods, with further carbonization at non-isothermal heating and activation at low temperature to $773-973 \mathrm{~K}$ in the presence $\mathrm{H}_{3} \mathrm{PO}_{4}$, lets to sorbents with a high exit rate (yield) of $80-90 \%$ and fractional composition particle size 1,0-3,6 mm (more $84 \%)$. These PCM can used in water treatment systems for water cleaning from solids, residual chlorine, organic compounds and odor and taste.

\section{References}

1. Kuzmin O., Shendrik T. (2016), Prospective assessment of the use of the carbonized wood waste of food industry for the production of activated carbon, Food Science for Well-being (CEFood 2016): 8th Central European Congress on Food 2016, 23-26 May 2016, Kyiv, NUFT, p. 109.

2. Sait Yorgun, Derya Yildiz (2015), Preparation and characterization of activated carbons from Paulownia wood by chemical activation with $\mathrm{H}_{3} \mathrm{PO}_{4}$, Journal of the Taiwan Institute of Chemical Engineers, 53, pp. 122-131.

3. Miroslaw Kwiatkowski, Dimitrios Kalderis, Evan Diamadopoulos (2017), Numerical 
analysis of the influence of the impregnation ratio on the microporous structure formation of activated carbons, prepared by chemical activation of waste biomass with phosphoric(V) acid, Journal of Physics and Chemistry of Solids, 105, pp. 81-85.

4. Arvind Kumar, Hara Mohan Jena (2017), Adsorption of Cr(VI) from aqueous phase by high surface area activated carbon prepared by chemical activation with $\mathrm{ZnCl}_{2}$, Process Safety and Environmental Protection, 109, pp. 63-71.

5. Aghdas Heidari, Habibollah Younesi, Alimorad Rashidi, AliAsghar Ghoreyshi (2014), Adsorptive removal of $\mathrm{CO}_{2}$ on highly microporous activated carbons prepared from Eucalyptus camaldulensis wood: Effect of chemical activation, Journal of the Taiwan Institute of Chemical Engineers, 45 (2), pp. 579-588.

6. Metin Acikyildiz, Ahmet Gurses, Semra Karaca (2014), Preparation and characterization of activated carbon from plant wastes with chemical activation, Microporous and Mesoporous Materials, 198, pp. 45-49.

7. Mohammad Amir Firdaus Mazlan, Yoshimitsu Uemura, Suzana Yusup, Fathelrahman Elhassan, Azhar Uddin, Ai Hiwada, Mitsutaka Demiya (2016), Activated Carbon from Rubber Wood Sawdust by Carbon Dioxide Activation, Procedia Engineering, 148, pp. 530-537.

8. B. Ruiz, N. Ferrera-Lorenzo, E. Fuente (2017), Valorisation of lignocellulosic wastes from the candied chestnut industry. Sustainable activated carbons for environmental applications, Journal of Environmental Chemical Engineering, 5 (2), pp. 1504-1515.

9. A. Ould-Idriss, M. Stitou, E.M. Cuerda-Correa, C. Fernandez-Gonzalez, A. Macias-Garcia, M.F. Alexandre-Franco, V. Gomez-Serrano (2011), Preparation of activated carbons from olive-tree wood revisited. I. Chemical activation with $\mathrm{H}_{3} \mathrm{PO}_{4}$, Fuel Processing Technology, 92 (2), pp. 261-265.

10. Felix A. Lopez, Teresa A. Centeno, Irene Garcia-Diaz, Francisco J. Alguacil (2013), Textural and fuel characteristics of the chars produced by the pyrolysis of waste wood, and the properties of activated carbons prepared from them, Journal of Analytical and Applied Pyrolysis, 104, pp. 551-558.

11. Geetha Selvaraju, Nor Kartini Abu Bakar (2017), Production of a new industrially viable green-activated carbon from Artocarpus integer fruit processing waste and evaluation of its chemical, morphological and adsorption properties, Journal of Cleaner Production, 141, pp. 989-999.

12. Tahira Mahmood, Rahmat Ali, Abdul Naeem, Muhammad Hamayun, Madeeha Aslam (2017), Potential of used Camellia sinensis leaves as precursor for activated carbon preparation by chemical activation with $\mathrm{H}_{3} \mathrm{PO}_{4}$; optimization using response surface methodology, Process Safety and Environmental Protection, 109, pp. 548-563.

13. George Tzvetkov, Simona Mihaylova, Katerina Stoitchkova, Peter Tzvetkov, Tony Spassov (2016), Mechanochemical and chemical activation of lignocellulosic material to prepare powdered activated carbons for adsorption applications, Powder Technology, 299, pp. 4150 .

14. Dobele G., Dizhbite T., Gil M.V., Volperts A., Centeno T.A. (2012), Production of nanoporous carbons from wood processing wastes and their use in supercapacitors and $\mathrm{CO}_{2}$ capture, Biomass and Bioenergy, 46, pp. 145-154.

15. Jiaojiao Kong, Qinyan Yue, Lihui Huang, Yuan Gao, Yuanyuan Sun, Baoyu Gao, Qian Li, Yan Wang (2013), Preparation, characterization and evaluation of adsorptive properties of leather waste based activated carbon via physical and chemical activation, Chemical Engineering Journal, 221, pp. 62-71.

16. Arvind Kumar, Hara Mohan Jena (2016), Preparation and characterization of high surface area activated carbon from Fox nut (Euryale ferox) shell by chemical activation with $\mathrm{H}_{3} \mathrm{PO}_{4}$, Results in Physics, 6, pp. 651-658. 
17. Juan Matos, Carol Nahas, Laura Rojas, Maibelin Rosales (2011), Synthesis and characterization of activated carbon from sawdust of Algarroba wood. 1. Physical activation and pyrolysis, Journal of Hazardous Materials, 196, pp. 360-369.

18. Akshay Jain, Rajasekhar Balasubramanian, M.P. Srinivasan (2016), Hydrothermal conversion of biomass waste to activated carbon with high porosity, Chemical Engineering Journal, 283, pp. 789-805.

19. Miroslaw Kwiatkowski, Vanessa Fierro, Alain Celzard (2017), Numerical studies of the effects of process conditions on the development of the porous structure of adsorbents prepared by chemical activation of lignin with alkali hydroxides, Journal of Colloid and Interface Science, 486, pp. 277-286.

20. Hiroyuki Wakizaka, Hajime Miyake, Yutaka Kawahara (2016), Utilization of beer lees waste for the production of activated carbons: The influence of protein fractions on the activation reaction and surface properties, Sustainable Materials and Technologies, 8, pp. $1-4$.

21. Piotr Nowicki, Justyna Kazmierczak, Robert Pietrzak (2015), Comparison of physicochemical and sorption properties of activated carbons prepared by physical and chemical activation of cherry stones, Powder Technology, 269, pp. 312-319.

22. Emine Yagmur, Meryem Ozmak, Zeki Aktas (2008), A novel method for production of activated carbon from waste tea by chemical activation with microwave energy, Fuel, 87 (15-16), pp. 3278-3285.

23. Shendrik T.G., Simonova V.V., Kucherenko V.A., Paschenko L.V., Khabarova T.V. (2003), Adsorption properties of activated carbon from lignin, Solid Fuel Chemistry, 41 (1), pp. $39-44$.

24. Kucherenko V.A., Shendrik T.G., Tamarkina Yu.V., Mysyk R.D. (2010), Nanoporosity development in the thermal - shock $\mathrm{KOH}$ activation of brown coal, Carbon, 48, pp. 45564558.

25. Zubkova V. (2011), Study on relation of solvent extractable material and resistivity of pyrolysed coal, Journal of Analytical and Applied Pyrolysis, 92, pp. 50-58.

26. Lillo-Rodenas M.A., Cazorla-Amoros D., Linares-Solano A. (2003), Understanding chemical reactions between carbons and $\mathrm{NaOH}$ and $\mathrm{KOH}$. An insight into the chemical activation mechanism, Carbon, 41(2), pp. 267-275.

27. Marsh H., Rodriguez-Reinoso F. (2006), Activated carbon, Amsterdam, Elsevier.

28. Brunauer S., Emmett P.H., Teller E. (1938), Adsorption of gases in multimolecular layers, J. Am. Chem. Soc., 60(2), pp. 309-319.

29. Barret E.P., Joyner L.C., Halenda P.P. (1951), The determination of pore volume and area distributions in porous substances. Computations from nitrogen isotherms, J. Am. Chem. Soc., 73 (1), pp. 373-380.

30. Tramer A., Kosewska M., Wróbelska K., Winnicka G. (2006), Wpływ dodatku emulsji smołowo-wodnej na zmianę budowy warstwy plastycznej węgla w procesie pirolizy, Karbo, 4, pp. 195-205.

31. Xiang-qian Zhang, Wen-cui Li, An-hui Lu (2015), Designed porous carbon materials for efficient $\mathrm{CO}_{2}$ adsorption and separation, New Carbon Materials, 30(6), pp. 481-501.

32. Ingo Burgert, Tobias Keplinger, Etienne Cabane, Vivian Merk, Markus Rüggeberg (2016), Chapter 13 - Biomaterial Wood: Wood-Based and Bioinspired Materials, Secondary Xylem Biology, 2016, pp. 259-281.

33. López-Garzón F.J., Fernandez-Morales I., Moreno-Castilla C., Domingo-García M. (1999), Carbon materials as adsorbents for vapour pollutants, Studies in Surface Science and Catalysis, 120(B), pp. 397-433.

34. Menéndez-Díaz J.A., Martín-Gullón I. (2006), Chapter 1. Types of carbon adsorbents and their production, Interface Science and Technology, 7, pp. 1-47. 